\title{
CARTA DE LOS EDITORES
}

\section{IUS ET SCIENTIA. REVISTA ELECTRÓNICA DE CIENCIA Y DERECHO. VOL II. No 1 (2016)}

Fiel a su vocación interdisciplinar científico-jurídica, el presente número 2 de la revista Ius et Scientia reúne una selecta colección de trece artículos doctrinales en los que se abordan diversas temáticas relacionadas con el bioderecho, la bioética, la biomedicina, la biología, la epistemología, la ética jurídica y los derechos humanos. El lector atento podrá comprobar que, en todos estos trabajos, se plantean cuestiones de gran relevancia científica que requieren ser analizadas en un foro de discusión teórico y práctico plural, crítico y transversal como el que representa nuestra revista.

En el primer artículo de este número 2, que responde al siguiente título: "Ubi societas, ubi ius: sobre las normas que organizan a los animales gregarios", su autor, Faustino Gudín Rodríguez-Magariños, parte de un sugerente estudio etológico-etnográfico que trasciende los límites de la antropología y en el que se someten a examen las formas organizativas de los animales gregarios. Animales y seres humanos comparten el instinto asociativo aunque sea en distintos grados de desarrollo, y esta es precisamente la premisa de la que parte el enfoque del autor de este estudio comparativo entre las pautas de comportamiento del mundo animal y las de la sociedad humana.

A su vez, José Manuel Sánchez Patrón dedica su artículo, titulado: "Los límites de la investigación biomédica en el ordenamiento jurídico internacional y europeo", a examinar cuáles son los principales retos a los 
que se enfrenta la investigación biomédica después del ostensible desarrollo que ésta ha experimentado a lo largo de las últimas décadas. Por otra parte, el autor pretende justificar la conveniencia de que la ciencia biomédica se someta a unos límites necesarios para salvaguardar los derechos fundamentales de los individuos, aunque haya que sacrificar los supuestos beneficios generales que puedan derivarse de las investigaciones científicas.

En el tercer artículo de este número Michele Zezza, reflexiona a propósito de: "La interpretación jurídica de los derechos fundamentales entre holismo metodológico y mecánica cuántica". Como desvela el propio autor, el objetivo de este estudio es intentar profundizar en algunas de las implicaciones epistemológicas de los cambios que han afectado a los procesos hermenéuticos dentro del marco del Estado constitucional contemporáneo, para poder realizar así un análisis crítico, de carácter interdisciplinar, de los fundamentos filosóficos de la ponderación entre derechos constitucionales. La hipótesis heurística que subyace a esta investigación es que a partir del examen de unos asuntos básicos de la física cuántica (y en particular, de un específico desarrollo en términos "relacionales" de la mecánica cuántica) puedan extraerse sugerencias para fortalecer una imagen de la interpretación judicial en términos de nounivocidad y no-objetividad.

La autora del cuarto artículo, Laura Gómez Abeja, dedica su estudio titulado: "Los ámbitos médico-científicos éticamente más controvertidos. Algunas propuestas para su regulación pacífica", a algunos de los temas más controvertidos de la ciencia médica desde un punto de vista éticojurídico, a saber: la interrupción voluntaria del embarazo, la reproducción asistida, la investigación biomédica y los derechos del paciente al final de su vida. De 
especial interés resultan las cuatro claves que aporta esta autora para resolver este tipo de conflictos: evitar el condicionamiento ideológico en el proceso dialógico, promover la libertad de conciencia, armonización del proceso legislativo con la dignidad humana y la ponderación de intereses jurídicamente relevantes que entran en conflicto.

El estudio de la prevención, como medida cautelar de reducción del riesgo de desastre, en la práctica internacional seguida por la UNESCO, es el tema desarrollado en el quinto artículo por Andrés Bautista-Hernáez: "Reflexiones en torno a la regulación jurídica de la reducción del riesgo de desastre y la práctica internacional al respecto seguida por la UNESCO”. De acuerdo con la opinión de este autor, las sinergias entre la Ciencia, Derecho y las medidas de reducción del desastre no solamente resultan de vital importancia, sino que resultan también extrapolables a todas las fases de gestión de las catástrofes. De aquí la relevancia que adquiere la labor de la UNESCO en materia de prevención, a pesar de que su papel jurídico-político en materia de prevención de desastres sea menos visible que su función más reconocida como agencia especializada de la ONU encargada por excelencia de la promoción de la educación, la ciencia y la cultura.

John Avilés Moreira es el autor del sexto artículo, titulado: "Gestación por sustitución: cambios en el reconocimiento de la filiación". En este estudio se pretende ofrecer una visión panorámica de la regulación nacional e internacional en la técnica de reproducción que genera un mayor debate ético-jurídico y mayor heterogeneidad normativa. El presente trabajo también nos aproxima al estudio de las jurisprudencia más actual y relevante del Tribunal Europeo de Derechos Humanos sobre esta materia, como por ejemplo las Sentencias Mennesson vs Francia y Labassee vs Francia.

Riccardo Perona es el autor del séptimo artículo, cuyo título es: "Razonamiento jurídico y método científico: apuntes para una taxonomía 
de los paradigmas en juego", parte de la investigación la relación existente entre el estudio del Derecho y del razonamiento jurídico, de un lado, y el estudio de la Ciencia y la metodología científica, de otro. Para este constitucionalista italiano, a pesar de la dificultad que entraña el empeño, debe buscarse un equilibrio entre ciencia o racionalidad y prudencia o racionabilidad, en el sentido de una ciencia incluyente de ambos aspectos prudenciales.

El octavo artículo, titulado: "Violación de los límites éticos reguladores de derechos fundamentales universales en biomedicina" es de Patricia Craviotto Valle. La premisa de partida del trabajo es la búsqueda de la unidad entre la ciencia biomédica y su regulación jurídica. A continuación, se realiza un estudio de los precedentes normativos a la legislación actual, y un análisis en términos comparativos entre la normativa latinoamericana y europea, con especial atención a la nueva ley de donantes de órganos en Gales (entró en vigor el 1 de diciembre de 2015), que ha dado lugar a una verdadera revolución en el seno del sistema de donación británico, provocando en la actualidad que el resto de Reino Unido.

María Sánchez Vilanova nos presenta un trabajo titulado: "Detección de mentiras: reflexiones desde la neuroética", en el que se centra en aspectos centrales derivados de la neurociencia cognitiva, como por ejemplo, las consecuencias jurídicas que la introducción de las pruebas neurocientíficas en el proceso judicial penal, como la conocida técnica de detección de mentiras (prueba P.300) pueden producir. Se trata de cuestiones ético-jurídicas vinculadas a la neuroética y que, pese a que tuvieron su inicio a finales de la década de los ochenta del pasado siglo, en los últimos años, han experimentado un ostensible crecimiento abordando aspectos como el consentimiento informado, la privacidad del pensamiento, 
o la predicción del comportamiento futuro en base a los principios morales que la Bioética ha ido desarrollando hasta nuestros días.

El siguiente artículo, centrado en la relación entre dignidad humana y biomedicina, está escrito por João Carlos Loureiro, y se titula: "Dignidad humana, (bio)medicina y revolución GNR (acrónimo de: Genética, Nanotecnología y Robótica): entre la Ciencia y el Derecho”. Según la tesis del autor de este trabajo, la relación entre biomedicina y dignidad humana en "tiempos líquidos", de "eugenesia liberal” y de tecnologías GNR permite confirmar que vivimos en un contexto muy marcado no solo por incertidumbres y riesgos, sino que nos encontramos ante dudas sobre el lugar y las posibilidades (bio)éticas y jurídicas en este campo.

Michele Zezza presenta un artículo titulado: "Ponderación judicial y holismo epistemológico", en el que el autor pretende aplicar algunas sugerencias teóricas del holismo epistemológico al ámbito de la ponderación judicial entre principios y derechos constitucionales. Frente a los planteamientos solipsistas y atomistas que aíslan los derechos (principios, valores, intereses, bienes etc.) en un espacio cerrado, o de posiciones holísticas y maximalistas, el autor entiende que una concepción coherentista y contextual del conocimiento puede ofrecer, en el campo de la interpretación jurídica, sugerencias teóricas para comprender que un margen más o menos amplio de indeterminación normativa es en cierto sentido fisiológico, dentro de un contexto de persistente conflictividad (sincrónica y diacrónica, intra-rights e inter-rights) como lo que caracteriza los Estados constitucionales contemporáneos.

Joaquín Garrido Martín, es autor del duodécimo artículo titulado: "Ciencia del Derecho en la Escuela Histórica y la Jurisprudencia de conceptos", en el que indaga sobre el origen de la Ciencia del derecho en la Alemania de principios del siglo XIX. Partiendo de la Pandectística, cuya 
metodología propone una vuelta a las fuentes, el autor realiza un sugerente recorrido por las principales corrientes iusfilosóficas que en aquél periodo abrieron una fractura en el hasta entonces infranqueable muro de la doctrina iusnaturalista: jurisprudencia de concepto y de intereses, historicismo jurídico, iuspositivismo, etc...

El autor del último artículo es Simone Penasa, cuyo título es: "El legislador frente a la Ciencia: reflexiones en perspectiva comparada", en el que se estudia la regulación de la actividad médica y de investigación científica por parte del legislador en el marco de un panorama normativo en donde, a juicio de este autor, la influencia de las fuentes internacionales resulta un elemento relevante a tener en cuenta en el proceso legislativo, aunque su alcance también se extiende a las demás fuentes del ordenamiento jurídico, a la jurisprudencia e incluso a la autorregulación de los médico-científicos.

Quisiéramos terminar señalando que, desde Ius et Scientia, trabajamos constantemente no solo para seguir publicando semestralmente en abierto contenidos de calidad científica, sino para conseguir que nuestra revista figure pronto en índices y bases de datos nacionales e internacionales. Esperamos poder obtener pronto resultados que avalen esta sincera apuesta por la investigación científico-jurídica rigurosa y la difusión del conocimiento en materias tan interdisciplinares como las que se concitan en este espacio abierto al debate y el intercambio de conocimientos. 